\title{
ANALYSIS OF CHEMICAL-METALLURGICAL AGGLOMERATION PROCESSES DURING CHARGE SINTERING
}

\author{
V. I. Bobkov ${ }^{1}$, M. I. Dli ${ }^{1}$, A. M. Sokolov ${ }^{1}$, Y. B. Rubin² \\ ${ }^{1}$ National Research University “Moscow Power Engineering Institute” - Smolensk Branch (Smolensk, Russia) \\ 2 Moscow University for Industry and Finance "Synergy"
}

E-mail: vovabobkoff@mail.ru; midli@mail.ru; Yrubin@synergy.ru

\section{A UTHOR'S INFO \\ V. I. Bobkov, Dr. Eng., Associate Prof. \\ M. I. Dli, Dr. Eng., Prof., A. M. Sokolov, Magister Student; \\ Y. B. Rubin, Dr. Econ., Prof., Head of the Dept. of Theory and Practice of Competition}

\section{Key words:}

agglomeration, coke fines, simulation, burning, heat exchange, drying, temperature, kinetics, power efficiency.

\section{A B S T RACT}

Thermally activated chemical and metallurgical processes of lumping of fine-dispersed iron ore raw material during sintering are examined in the work. The following processes are included: moisture removal, ignition of coke fines and burn-off of carbonates, taking into account burning features of coke fines, fusion of grain charge, forming of agglomeration cake, creation of overhumidification area in sintering layer owing to condensation of water vapours in washout of heat-carrying gas. Parameters of sintering kinetics are obtained experimentally, other parameters characterizing layer shrinkage of sintering charge are presented. It was established that the temperature in the sintering area has substantial effect on shrinkage. The presented temperature relationship describes experimental data with sufficient precision. The values of power exchange coefficients in the drying area are examined. The criteria equations of heat and mass exchange are presented.

The mathematical model using empiric material is proposed; it describes sintering kinetics for agglomeration charge, taking into account layer shrinkage and variation of head losses in technological areas of fusion and forming of ready agglomerate, what corresponds well with the experimental data. Multi-factor relationship between chemical and metallurgical processes (from one side) and heat and mass exchange in the sintering layer of agglomeration charge (from other side) is noted. Adequacy of mathematical models allows to use them for analysis of high-efficient conditions of agglomerate fabrication.

\section{Introduction}

Agglomeration of fine-dispersed raw materials at belt-type conveyors is the main method of lumping of ore fines for metal production in metallurgical industry. Fine-dispersed ore raw materials is mixed with coke fines and corresponding components necessary for obtaining of the required properties of finished product; then it is preliminarily pelletized and laid in the sintering layer of charge at the conveyor of a sintering machine (presented by special sintering cars - pallets) [1]. Then the upper level of charge is heated up to the temperature of fuel ignition while moving in the hearth of a sintering machine. After processing in the hearth, the sintering charge is subjected to air washout, what provides steady burning [2]. Speed of conveyor motion is determined by the conditions of burning finishing [3]. Heated agglomeration cake is transferred to crusher and sieve and afterwards the obtained lump material is subjected to cooling [4].

As soon as agglomeration in metallurgy is accompanied by essential consumption of raw materials and power, the problem of power supply is rather actual.

The aim of this work is the complex analysis of mutually depending chemical and metallurgical processes occurring during agglomeration of iron ore fines, in order to improve power and resource efficiency.

\section{Conditions of analyzed agglomeration process}

Analysis of agglomeration process was conducted in the following conditions: part of concentrate 61-
$66 \%$; part of carbon in charge $4 \%$; charge humidity 5-7\%; return part $25-30 \%$; height of charge layer $150-200 \mathrm{~mm}$.

Material and heat balance of the process of iron ore fines agglomeration (per $100 \mathrm{~kg}$ of agglomerate) are presented in the tables $\mathbf{1}$ and 2.

Attention should be attracted in consumption items to heat of waste gases, heat of agglomeration cake and wastes in the environment.

\section{Physical and chemical transformations in raw materials during agglomeration}

Agglomeration of fine-dispersed iron ore raw materials is a high power-efficient technological process meaning its heat and power conditions [5]. The sintered layer in the burning area is practically completely melted at rather

\begin{tabular}{|c|c|c|c|c|c|}
\hline \multicolumn{6}{|c|}{ Table 1. Material balance of agglomeration process } \\
\hline Income item & $\mathrm{kg}$ & $\%$ & $\begin{array}{c}\text { Consumption } \\
\text { item }\end{array}$ & $\mathrm{kg}$ & $\%$ \\
\hline $\begin{array}{c}\text { Iron ore materials } \\
\text { and metal } \\
\text { additived }\end{array}$ & 74.94 & 25.56 & Agglomerate & 100 & 34.1 \\
\hline Flux & 31.32 & 10.68 & Waste gases & 190.04 & 64.81 \\
\hline Coke fines & 11.65 & 3.97 & $\begin{array}{c}\text { Agglomeration } \\
\text { dust (slime) }\end{array}$ & 3.2 & 1.09 \\
\hline Gas for ignition & 0.88 & 0.3 & & & \\
\hline Air for sintering & 157.06 & 53.56 & & & \\
\hline Charge moisture & 17.39 & 5.93 & & & \\
\hline Total amount & 293.24 & 100 & Total amount & 293.24 & 100 \\
\hline
\end{tabular}




Table 2. Heat balance of agglomeration process
\begin{tabular}{|l|c|c|c|c|c|}
\hline \multicolumn{1}{|c|}{ Income item } & кДж & $\%$ & $\begin{array}{c}\text { Consumption } \\
\text { item }\end{array}$ & кДж & $\%$ \\
\hline Fuel burning & 236014 & 82.55 & $\begin{array}{c}\text { Evaporation } \\
\text { of hygroscopic } \\
\text { moisture }\end{array}$ & 39258 & 13.73 \\
\hline Fe $_{2}$ S and FeS & 1828 & 0.64 & $\begin{array}{c}\text { Removal } \\
\text { of hydrate } \\
\text { moisture }\end{array}$ & 11788 & 4.12 \\
\hline Charge heat & 2963 & 1.04 & $\begin{array}{c}\text { Dissociation } \\
\text { of carbonates }\end{array}$ & 19060 & 6.67 \\
\hline Air heat & 3133 & 1.10 & $\begin{array}{c}\text { Decomposition } \\
\text { of complicated } \\
\text { minerals }\end{array}$ & 983 & 0.34 \\
\hline Ignition & 34000 & 11.89 & $\begin{array}{c}\text { Heat of waste } \\
\text { gases }\end{array}$ & 55052 & 19.26 \\
\hline FeO oxidation & 919 & 0.32 & Heat of cake & 101174 & 35.39 \\
\hline Silicate forming & 7050 & 2.47 & Charge melting & 15493 & 5.42 \\
\hline & & & Heat losses & 43099 & 15.07 \\
\hline Total amount & 285907 & 100 & Total amount & 285907 & 100 \\
\hline
\end{tabular}

small consumption of coke fines (4-8\%) and is consequently crystallized as porous cake (agglomerate) [6].

Heat power can be regenerated based on rational organization of the technological process, what allows to rise power efficiency approximately by $40 \%$. Removal of moisture is rather power-intensive process, and it has significant effect on power engineering and technology of agglomerate sintering in the layer [7].

Mutual influencing physical and chemical transformation processes 6 being essentially depended on the conditions of heat and mass exchange [8] are occurred simultaneously at different heights of sintered layer in agglomeration charge. The following transformations can be mentioned here: moisture evaporation, ignition of coke fines, burning of coke fuel and fusion of charge particles, endothermic decarbonization and other chemical reactions, condensation of moisture vapours in the lower levels of sintered layer, agglomeration cake forming.

High intensity of heat exchange between heat-carrying gas and charge particles can be provided owing to rather developed surface of charge particles and fuel burning inside sintered layer; high power efficiency of heat power usage is achieved as well [9]. In agglomeration process, air for fuel burning is washing out through sintered layer and provides heat recuperation from more heated upper levels if sintered layer of agglomeration charge to less heated lower levels. Therefore, heat and power exchange can be characterized as regeneration process [10]. Speed of transition of agglomerate in burning area from top downward in the sintered layer depends on heat and mass exchange as well as physical and chemical transformations and is described by the heat balance equation for elementary layer.

$$
\Delta h \rho_{m}(1-\varepsilon) c_{m} \Delta t_{m}=w_{g} \Delta \tau \rho_{g} c_{g} \Delta t_{g},
$$

where $\Delta t_{m}, \Delta t_{g}$ - temperature variations of charge materials and heat-carrying gas on the elementary layer section with height $\Delta h$, during elementary time period $\Delta \tau ; c_{g}$, $c_{m}$ - gas heat capacity and apparent charge heat capacity, including heat absorption and extraction as a result of en- dothermic and exothermic processes; $\varepsilon$ - porosity of sintered layer; $w_{g}$ - washout speed of heat-carrying gas; $\rho_{m}$ density of charge material; $\rho_{g}$ - density of heat-carrying gas. Dimensions of all values included in the equations are suggested to be in the International System of Units (SI).

Sintering speed is proportional to filtration speed of heat0carrying gas and depends on charge material properties

$$
u=\Delta h / \Delta \tau=\left(w_{g} \rho_{g} c_{g} \Delta t_{g}\right) /\left(\rho_{m}(1-\varepsilon) c_{m} \Delta t_{m}\right) .
$$

In general case, it is necessary to evaluate heat capacity of charge material $c_{m}$ for assessment of sintering and agglomerate fabrication speed, taking into account kinetic features of phase transformations in charge, fuel burning and non-isothermal processes of carbonates dissociation with heat effects of decomposition of $\mathrm{CaCO}_{3}$ $(Q=1778 \mathrm{~kJ} / \mathrm{kg})$ и $\mathrm{MgCO}_{3}(Q=1395 \mathrm{~kJ} / \mathrm{kg})$. Kinetics of decarbonization is considered by the authors in $[11,12]$ and obtained results were used for analysis of dissociation processes of carbonates during agglomeration.

Fuel burning in sintered layer of agglomeration charge has its own features. This process is usually presented as two reactions occurring simultaneously:

a) $\mathrm{C}+\mathrm{O}_{2}=\mathrm{CO}_{2}+410 \mathrm{MJ} / \mathrm{kmol}$;

b) $\mathrm{C}+0,5 \mathrm{O}_{2}=\mathrm{CO}+124 \mathrm{MJ} / \mathrm{kmol}$.

With temperature rising, the second reaction is most possible. The conditions for sold phase reduction appear. The opposite tendency can be observed at increase of gas phase pressure. The speed of oxidant feed to the surface of reacting particles has the effect on reaction process. The picture of heterogeneous burning varies depending on the relationship between oxygen diffusion processes and reaction speed.

Internal porous reaction is also possible in kinetic conditions, while only surfacial reaction can be observed in diffusion conditions. The constant of specific surfacial speed of carbon burning can be presented as $k_{s}^{c}=\beta_{c} C_{\mathrm{O}_{2}}\left(1 / k+1 / \alpha_{D}\right)^{-1}$ where: $\beta_{c}-$ stoichiometric coefficient within the range $0.37-0.75$ depending on reaction via the mechanism a) or b); $C_{\mathrm{O}_{2}}$ - oxygen concentration; $k$ - the constant of burning speed of a solid fuel particle; $\alpha_{D}-$ mass exchange coefficient determining via criteria equations: for freely burning particles $\mathrm{Nu}_{\mathrm{D}}=2\left(1+0,08 \operatorname{Re}^{2 / 3}\right)$. For the particles burning in layer: $\mathrm{Nu}_{\mathrm{D}}=0,187 \operatorname{Re}$, when $7 \leq \operatorname{Re} \leq 27$ or $\mathrm{Nu}_{\mathrm{D}}=0,01 \mathrm{Re}^{2,5}$, when $\operatorname{Re}<7$; where $\mathrm{Nu}_{\mathrm{D}}=\alpha_{D} d_{c} / D, d_{c}-$ coke particle diameter; $D$ - oxygen diffusion coefficient.

The equation describing burn-off of a coke particle in layer is as follows:

$$
d\left(\rho_{c} \pi d_{c}^{3} / 6\right)=-k_{s}^{c} \pi d_{c}^{2} d \tau .
$$

The main task of agglomeration technology of iron ore fines is lumping. Agglomerate lumps should meet the requirements in strength, they also should be characterized by easy reducibility. Agglomerate forming via sintering occurs in the temperature range 


\begin{tabular}{|c|c|c|c|c|c|c|c|}
\hline $\begin{array}{c}\text { Size } \\
\text { of particles, } \\
\mathrm{mm}\end{array}$ & $t,{ }^{\circ} \mathrm{C}$ & $\begin{array}{c}\mu_{m} \cdot 10^{-6}, \\
\text { Pa.s }\end{array}$ & $n$ & $\begin{array}{c}\text { Size } \\
\text { of particles, } \\
\mathrm{mm}\end{array}$ & $t,{ }^{\circ} \mathrm{C}$ & $\begin{array}{c}\mu_{m} \cdot 10^{-6} \\
\text { Pa.s }\end{array}$ & $n$ \\
\hline $0.14-0$ & 1250 & 4.4 & 0.68 & $0.2-0.14$ & 1100 & 230 & 0.78 \\
\hline $0.2-0.14$ & 1250 & 4.4 & 0.68 & $0.063-0$ & 1200 & 20 & 0.72 \\
\hline $0.14-0$ & 1200 & 12 & 0.74 & $0.1-0.063$ & 1200 & 20 & 0.72 \\
\hline $0.2-0$ & 1200 & 12 & 0.74 & $0.16-0.1$ & 1200 & 20 & 0.72 \\
\hline $0.2-0.14$ & 1200 & 12 & 0.74 & $0.063-0$ & 1150 & 42 & 0.75 \\
\hline $0.14-0$ & 1150 & 38 & 0.76 & $0.1-0.063$ & 1150 & 42 & 0.75 \\
\hline $0.2-0$ & 1150 & 38 & 0.76 & $0.16-0.1$ & 1150 & 42 & 0.75 \\
\hline $0.2-0.14$ & 1150 & 38 & 0.76 & $0.063-0$ & 1100 & 48 & 0.76 \\
\hline $0.14-0$ & 1100 & 230 & 0.78 & $0.1-0.063$ & 1100 & 48 & 0.76 \\
\hline $0.2-0$ & 1100 & 230 & 0.78 & $0.16-0.1$ & 1100 & 48 & 0.76 \\
\hline
\end{tabular}

$800-1500{ }^{\circ} \mathrm{C}$. Sintering of agglomeration charge starts from solid phase processes and finishes by melt forming. Development of solid phase processes depends on properties of iron ore raw material and thermal conditions of lumping, while thermal conditions provide charge melting; there is no other way to provide fabrication of strong agglomerate.

The main regularities of the sintering theory are described in the works of different authors [13-15] and, according to them, sintering can be realized via the following ways [16]:

tough flow, i.e. via directed transition of substance to a contact isthmus with increase of contact square;

volumetric and boundary diffusion, i.e. via transition of substance with increased contact of particles without approximation of their centers;

transition of substance through gaseous phase owing to difference between equilibrium vapours pressure near concave and convex sections of shapes of contacting particles.

\section{Simulation of chemical and metallurgical processes occurring in charge during heating}

Use of the above-mentioned mechanisms in the sintering models allow to obtain relationship $\left(x / r_{m}\right)^{n}=A \tau$, where $x$ - radius of sintering area, $\tau-$ time; $r_{m}-$ radius of sintering particles; $n=2, A=1.5 \sigma_{t}\left(\mu, r_{m}\right)$ - for the mechanism of tough flow; $n=5, A=20 \pi \sigma_{t} /\left(k t_{m} r_{m}^{3}\right)$ - for volumetric self-diffusion with drain of vacancies to the surface; $n=5, A=80 a^{3} \sigma_{t} D_{p} /\left(k t_{m} r_{m}^{3}\right)-$ with drain of vacancies to the contact boundary; $n=6$, $A=48 a^{3} \sigma_{t} D_{\mathrm{B}} /\left(k t_{m} r_{m}^{4}\right)$ - for boundary self-diffusion; $n=7, A=28 a^{3} \sigma_{t} \delta D_{s} /\left(k t_{m} r_{\mathrm{M}}^{4}\right)$ - for surfacial self-diffusion; $n=3, A=(28 / \pi)^{1 / 2}\left(m / k t_{m}\right)^{3 / 2} \delta_{t} P_{0} /\left(\rho_{m} r_{m}^{2}\right)-$ for transfer of substance through gaseous phase at small gas pressures; $n=5, A=\left(40 a^{4} \sigma_{t} P_{0}\right) /\left(\pi r_{m}^{3}\left(6 m k t_{m}\right)^{1 / 2} P_{z}\right)-$ at large pressures; $D_{p}, D_{s}$ - coefficients of boundary and surfacial diffusion; $k$ - Bolzmann constant; $a$ - lattice period; $m-$ mass of a substance molecule; $\delta$ - with of the area where surfacial or boundary diffusion takes place; $P_{z}-$ excessive pressure; $\sigma_{t}-$ coefficient of melt surface tension; $\mu_{m}-$ dynamic toughness.
Application of rheological models allows to connect volumetric deformation and tension via the following equation

$$
d \varepsilon / d \tau=\left(2 \sigma_{t}\right) /\left[4 / 3 \mu_{m}(1-\varepsilon)^{2} r_{m}\right]
$$$$
\Delta V / V=\Delta \varepsilon /(1-\varepsilon) \text {. }
$$

Integrating the equation (1) we get

$$
\ln \left(\varepsilon_{0} / \varepsilon\right)=1.5\left(\sigma_{t} / r_{m} \mu_{m}\right) \tau \text {. }
$$

Analysis of influence of lumping conditions on agglomerate strength can be conducted, taking into account correlation between porosity and strength, which is expressed by different relationships, based on the data of different authors $[17,18]$. This research use the following formula in calculating experiments: $\sigma=\sigma_{k}\left[1-1.5 \varepsilon\left(1+2 k_{s}\right)+4.5 k_{s} \varepsilon^{2}\right]$, where $k_{s}$ - empiric coefficient of attenuation; $\sigma-$ agglomerate strength; $\sigma_{k}-$ final agglomerate strength.

\section{Discussion of experimental and numerical results obtained on the models}

The results of experimental researches of sintering kinetics for iron ore fines are described well by the relationship of the following type (1):

$$
\Delta l / l=0.75\left(\sigma_{t} / r_{m} \mu_{m}\right) \tau^{n}
$$

The values of parameters for shrinkage evaluation of sintered charge are presented in the Table 3.

Surface tension increases and toughness decreases with rise of basicity of sintered material (acidity index was experimentally varied from 0.1 to 0.5$)[19,20]$. Therefore, the tough flow mechanism prevails in sintering of agglomeration charge. Both factors provide enlargement of agglomerate strength [21].

The experimental data on kinetics of isothermal sintering (Fig. 1) testify that the temperature in the sintering area has essential effect on shrinkage.

The temperature relationship with sufficient practical accuracy can be described in the exponential form: $A_{1}=k_{s} \exp \left(-E_{c} / t_{m}\right)$, where $A_{1}$ is included in the equation for shrinkage as $\Delta l / l=\left(A_{1} \tau\right)^{n}$. The values $E_{A}$ and $n$ are presented in the Table 4.

In the process of sintering, gas dynamic layer resistance increases, what has in its turn the effect on the conditions of mass transfer [17]. Gas dynamic resistance of sintered layer elevates by $10-15$ times in comparison with initial charge layer.

Moreover, resistance values differ essentially in different layer areas $[18,22]$. The following relationship is true for gas dynamic resistance:

$$
\Delta P / \Delta h=\rho_{g_{0}} W_{g_{0}}\left(k_{g_{1}} v_{g_{t}}+k_{g_{2}} W_{g_{0}}\left[t_{g} / t_{g_{0}}\right]\right) .
$$

where $\rho_{g_{0}}, W_{g_{0}}$ - density and speed of gases at normal conditions; $v_{g_{t}}$ - kinematic gas toughness at the temperature $t_{g} ; k_{g_{1}}, k_{g_{2}}$ - empiric coefficients. 

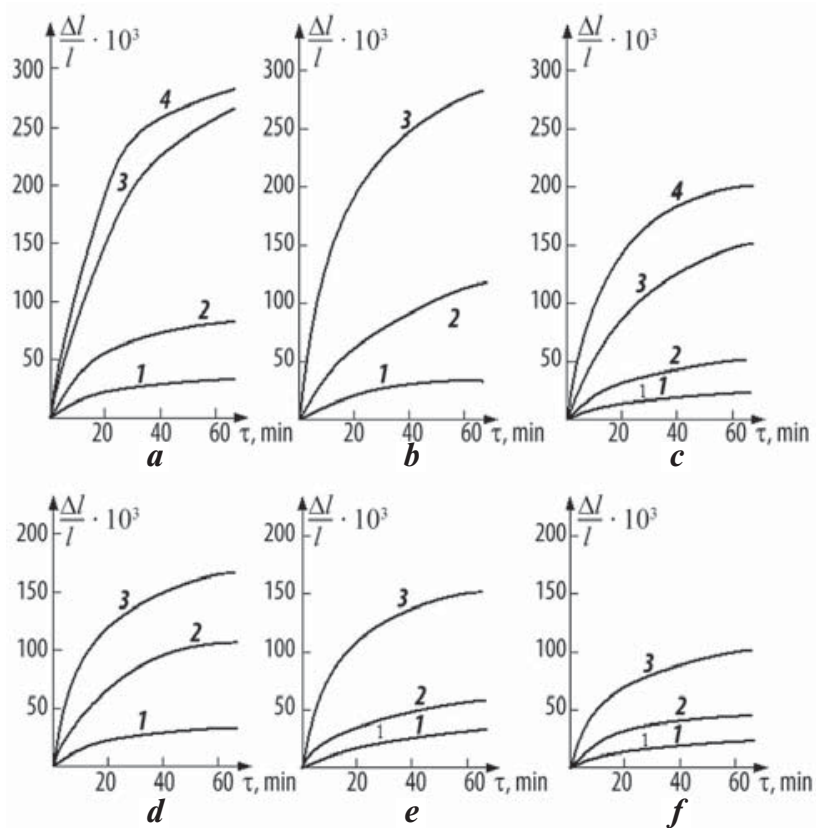

Fig. 1. Experimental shrinkage values during isothermal sintering:

$1-1100{ }^{\circ} \mathrm{C} ; 2-1150{ }^{\circ} \mathrm{C} ; 3-1200{ }^{\circ} \mathrm{C}$;

$4-1250{ }^{\circ} \mathrm{C} ; 5-\min ; a-c-$ ore fines with lump

size $0.14-0 ; 0.2-0 ; 0.2-0.14 \mathrm{~mm}$ respectively;

$d-f-$ coke fines with lump size $0.063-0$;

$0.1-0.63 ; 0.16-0.1 \mathrm{~mm}$ respectively

\begin{tabular}{|c|c|c|c|c|c|c|}
\hline \multicolumn{7}{|c|}{$\begin{array}{l}\text { Table 4. Values of empiric coefficients } E_{c} \text { and } n \text { in the equation for } \\
\text { shrinkage depending on temperature }\end{array}$} \\
\hline & \multirow{2}{*}{$\begin{array}{l}\text { Size of particles, } \\
\mathrm{mm}\end{array}$} & \multicolumn{4}{|c|}{$n$ at the temperature, ${ }^{\circ} \mathrm{C}$} & \multirow{2}{*}{$E_{\mathrm{c}} \cdot 10^{-3}, 1 / \mathrm{K}$} \\
\hline & & 1100 & 1150 & 1200 & 1250 & \\
\hline \multirow{3}{*}{$\begin{array}{l}\text { Ore } \\
\text { fines }\end{array}$} & $0.14-0$ & 0.36 & 0.78 & 0.64 & 0.61 & 39.37 \\
\hline & $0.2-0$ & 0.81 & 0.77 & 0.72 & - & 39.69 \\
\hline & $0.2-0.14$ & 0.79 & 0.80 & 0.70 & 0.60 & 39.5 \\
\hline \multirow{3}{*}{$\begin{array}{l}\text { Coke } \\
\text { fines }\end{array}$} & $0.063-0.077$ & 0.77 & 0.74 & 0.72 & - & 35.8 \\
\hline & $0.1-0.063$ & 0.78 & 0.74 & 0.73 & - & 37.02 \\
\hline & $0.16-0.1$ & 0.79 & 0.76 & 0.68 & - & 38.65 \\
\hline
\end{tabular}

\begin{tabular}{|c|c|c|}
\hline \multicolumn{3}{|c|}{$\begin{array}{l}\text { Table 5. Average values of the empiric coefficients } \boldsymbol{k}_{g_{1}}, \boldsymbol{k}_{g_{2}} \\
\text { of agglomerating charge }\end{array}$} \\
\hline Area & $k_{g} \cdot 10^{-5}, m^{-2}$ & $k_{g_{2}}, \mathrm{~m}^{-1}$ \\
\hline Agglomerate cake & $12-16$ & $80-120$ \\
\hline Melting & $10-13$ & $30-60$ \\
\hline Intensive heating & $8-10$ & $6-20$ \\
\hline Drying & $2-5$ & $6-14$ \\
\hline Overhumidification & $2-3$ & $4-6$ \\
\hline Initial charge & $1-3$ & $4-6$ \\
\hline
\end{tabular}

The average values of the coefficients for phosphoritic agglomerating charge in different areas are presented in the Table 5.

Temperature measurements for particles of damp agglomerate charge were conducted during its drying in four points along the layer height for examination of heat transfer coefficients. The layer height of drying charge made $130 \mathrm{~mm}$. The temperature of heat carrier fed from a diesel fuel burning chamber to the layer with speed $0.3-$ $1.0 \mathrm{~m} / \mathrm{s}$ was $920{ }^{\circ} \mathrm{C}$. Thermocouples for measuring the

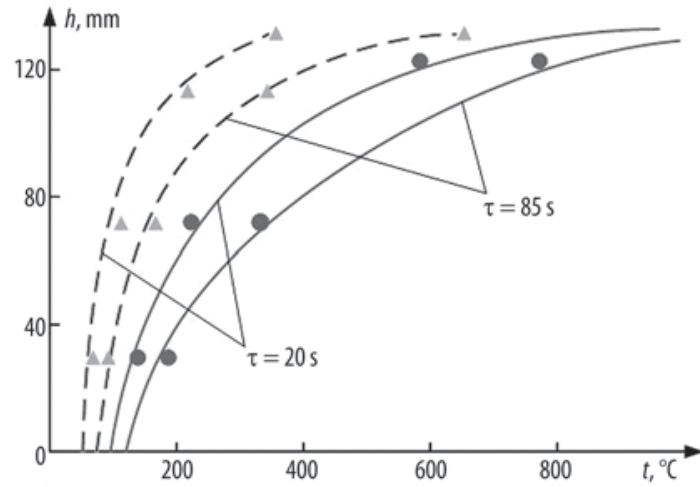

Fig 2. Distribution of gas temperature and charge during drying:

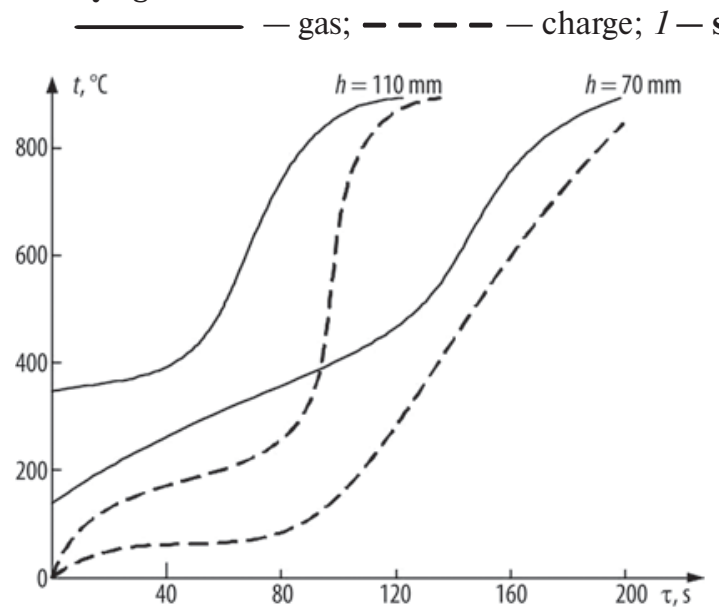

Fig 3. Values of gas temperature and charge in the sintering layer at $h=110 \mathrm{~mm}$ and $h=70 \mathrm{~mm}$ during drying process:

- - gas; - - - - charge; $1-\mathrm{s}$

temperature of agglomerate charge lumps and gas were located along the layer height $h=30,70,110,130 \mathrm{~mm}$. The following graphs illustrating distribution of the temperature of heat-carrying gas and agglomerating charge along the layer height were built (Fig. 2).

Heat transfer coefficient $\alpha_{F}$ was evaluated from the relationship $\alpha_{F}=\rho_{g} c_{g} W_{g}\left(\partial t_{g} / \partial y\right) /\left(t_{g}-t_{m}\right) f_{F}$, where $f_{F}-$ specific surface in the sintering layer.

This relationship was used at the time when the drying front reached the level, where the measurements were conducted. Evaluation of heat transfer coefficient was done at two upper levels at $h=110 \mathrm{~mm}$ and $h=70 \mathrm{~mm}$. Location of the drying front was determined via the charge temperature field. The experimental results are presented in criteria form as follows: $\mathrm{Nu}=2+0,42 \mathrm{Re}^{0,6} \mathrm{Pr}^{0,33}$. Transfer speed of the moisture evaporation front can be found through transfer of the section typical for drying finishing, when charge starts to be heated intensively (Fig. 3).

Comparison of charge heating conditions for two layers allowed to obtain the value of drying speed $0.81 \mathrm{~m} / \mathrm{s}$ at washout speed of drying agent (heat-carrying gas) $w_{g}=0,7 \mathrm{~m} / \mathrm{s}$. Low accuracy of the results (about $30 \%$ ) is explained by the errors in calculation of gas consumption at the points of thermocouples mounting, be evaluating 
determination $f_{F}$ of composition of burning products, by approximate building of the temperature field and by numerical differentiation.

\section{Conclusions}

It is necessary to have trustworthy information about the processes of moisture exchange and heat exchange as well as thermal hydraulics during washing out of hot gases through the layer, to provide rational holding of ignition process of coke fines [23]. Heat exchange in the dispersed layer during coke heating, coke burning and moisture removal runs very intensively owing to very developed surface in the volume of dispersed layer [24]. The processes connected with the aimed process (agglomeration cake fabrication) influence on power exchange intensity.

The mass exchange processes are determined in general by multiple factors, what pre-define building of generalized relationships, taking into account the effect of the following factors: conditions of heat exchange; layer structure; properties of substances subjected to drying; humidity of heat carrier; temperature; thermal physical properties of heat-carrying gas etc.

Obtaining of semi-empiric relationships for description of complete totality of appearances during agglomeration is directed on solving of the problems of process management and search of optimal conditions for fabrication of finished products.

\section{Summary}

Agglomeration processes allowing to evaluate adequacy of mathematical models for analysis of high-efficient conditions of agglomerate fabrication are conducted and researched.

Parameters of relationships for description of sintering and drying processes, hydraulic resistance and heat exchange coefficients are obtained.

The range of varying the initial data in the research allows to use the results for wide variety of agglomeration processes.

The research was conducted under financial support of the Russian Foundation of Basic Research (RFFI within the framework of the scientific project No. 18-29-24094 MK and in accordance with the State assignment, the project No. FSWF-2020-0019.

\section{REFERENCES}

1. Melamud S. G., Yuryev B. P. Oxidation of iron ore at moderate and high temperatures. Steel in Translation. 2016. Vol. 46. No. 6. pp. 384-389.

2. Chen Y., Shi L., Du J., Zhang H., Jiao X. Preparation and Properties of the Lightweight Thermal Insulation Wall Materials with Iron Tailings. Journal of Building Materials. 2019. Vol. 22(5), pp. 721-729.

3. De Gisi S., Romaniello L., Dalessandro M., Todaro F., Notarnicola M. Recovery of iron rich residues from integrated steel making process by hydrated lime/molasses pressurised cold agglomeration. Journal of Cleaner Production. 2019. Vol. 233. pp. 830-840.

4. Shapovalov A. N. Use of agglomerate cake heat for additional heating of agglomeration charge. Teoriya i tekhnologiya metallurgicheskogo proizvodstva. 2018. No. 4(27). pp. 32-36.

5. Ganin D. R., Druzhkov V. G., Panychev A. A., Bersenev I. S. Microstructure and mineralogical composition of agglomerates in use of additives of brown ironstone ores, bentonite clays and serpentinite-magnesites. Chernye metally. 2018. No. 5. pp. $10-14$

6. Mnykh A. S., Dovgal V. V., Shumikin S. A. Management on distribution of agglomeration charge along layer height in a sintering machine with different conditions of its charging. Metalurgiya. 2018. No. 1(39). pp. 109-114.

7. Yuan S., Zhou W., Han Y., Li Y. Efficient enrichment of lowgrade refractory rhodochrosite by preconcentration-neutral suspension roasting-magnetic separation process. Powder Technology. 2020. Vol. 361. pp. 529-539.

8. Yang X.-F. Mechanism of roasting and agglomeration on the pellets produced by blended iron ore fines of hematite and magnetite. Journal of Iron and Steel Research. 2010. Vol. 22. No. 2. pp. 6-8

9. Luis P., Van der Bruggen B. Energy analysis of energy-intensive production processes: advancing towards a sustainable chemical industry. Journal of Chemical Technology and Biotechonology. 2014. Vol. 89. No. 9. pp. 1288-1303.

10. Shapovalov A. N. Improvement of agglomerate quality in the conditions of "Ural Steel” JSC. Tekhnologii metallurgii, mashinistroeniya i metalloobrabotki. 2017. No. 16. pp. 10-20.

11. Bobkov V. I., Borisov V. V., Dli M. I., Meshalkin V. P. Study of the Thermal Characteristics of Phosphate Raw Materials in the Annealing Temperature Range. Theoretical Foundations of Chemical Engineering. 2017. Vol. 51. No. 3. pp. 307-312.

12. Bobkov V. I., Borisov V. V., Dli M. I., Meshalkin V. P. Thermally activated chemical technology processes of agglomeration of phosphorites. Theoretical Foundations of Chemical Engineering. 2018. Vol. 52. No. 1. pp. 35-41.

13. Skorokhod V. V. Rheological grounds of the sintering theory. Kiev: Naukova dumka. 1972. 147 p

14. Korotich V. I., Frolov Yu. A., Bezdezhskiy G. N. Agglomeration of ore materials. Ekaterinburg: GOU VPO "UGTUUPI". 2003. 400 p.

15. Bazilevich S. V., Vegman E. F. Agglomeration. M.: Metallurgiya. $1967.368 \mathrm{p}$

16. Geguzin Ya. E. Physics of sintering. M.: Nauka. 1984. 312 p.

17. Fan X.-H., Gan M., Jiang T., Yuan L.-S., Chen X.-L. Influence of flux additives on iron ore oxidized pellets. Journal of Central South University of Technology (English Edition). 2010. Vol. 17. No. 4. pp. 732-737.

18. Kowalska J., Kowalska H., Cieślak B. et al. Influence of sucrose substitutes and agglomeration on volatile compounds in powdered cocoa beverages. Journal of Food Science and Technology. 2020. Vol. 57(1). pp. 350-363.

19. Panchenko S. V., Shirokikh T. V. Thermophysical processes in burden zone of submerged arc furnaces. Theoretical Foundation of Chemical Engineering. 2014. Vol. 48. No. 1. pp. 77-83.

20. Matyukhin V. I., Yaroshenko Yu. G., Bragin V. V. Technological possibilities of production of iron ore agglomerate with use of combined fuel. Stal. 2019. No. 11. pp. 3-8.

21. Frolov Yu. A., Aggarwal N., Polotskiy L. I. Study of agglomeration process with recirculation of waste gases. Metallurg. 2017. No. 8. pp. 25-32

22. Meshalkin V. P., Bobkov V. I., Dli M. I., Fedulov A. S. Mathematical simulation of chemical and energotechnological processes and procedures of coke fines burning in agglomerated layer. CIS Iron and Steel Review. 2020. Vol. 19. pp. 13-17.

23. Cui L., Ba K., Li F. et al. Life cycle assessment of ultra-low treatment for steel industry sintering flue gas emissions. Science of the Total Environment. 2020. 725,138292.

24. Hu S., Li J., Yang X. et al. Improvement on slurry ability and combustion dynamics of low quality coals with ultra-high ash content. Chemical Engineering Research and Design. 2020. Vol. 56. pp. 391-401. 